\title{
An acute oral administration of Sildenafil in asthenozoospermic patients improves sperm motility after density gradient centrifugation
}

Felipe A. Morales Martínez ${ }^{1}$, Martha Merino Ruiz' ${ }^{1}$, Eddy E. Angulo Velarde ${ }^{1}$, Otto H. Valdés Martínez ${ }^{1}$, Sara P. Peña Lizola ${ }^{1}$, Luis H. Sordia Hernández ${ }^{1}$

${ }^{1}$ Centro Universitario de Medicina Reproductiva, Hospital Universitario "Dr. José Eleuterio González", Universidad Autónoma de Nuevo León, Monterrey, Nuevo León, México

\begin{abstract}
Objective: Investigate the possible effect of an acute sildenafil dose in asthenozoospermic patients.

Methods: We ran this experimental, descriptive, prospective and non-blinded study in 32 patients diagnosed with asthenozoospermia according to the WHO criteria, after two consecutive semen analyses (samples 1 and 2 ), and we asked them to provide a new semen sample two weeks after the initial exams (sample 3 ). One hour prior to the semen collection, we gave the patients $100 \mathrm{mg}$ oral sildenafil. Samples 2 and 3 were allowed to liquefy and density gradients centrifugation was performed. We assessed sperm motility by Computer-assisted sperm analysis (CASA).

Results: There were no significant differences between the samples obtained before (sample2) or after sildenafil administration (sample3). However, a single oral $100 \mathrm{mg}$ sildenafil dose in asthenozoospermic patients increase the percentage of motile sperm recovered after density gradient centrifugation.

Conclusions: An acute administration of sildenafil enhances sperm recovery after density gradient centrifugation in asthenozoospermic patients, and it may produce more available mobile sperm to perform intra uterine insemination or to improve the chances of success in this procedure. This approach may be used as an alternative strategy in assisted reproductive programs. Sildenafil was well tolerated and no patient was withdrawn from the study due to adverse events attributed to sildenafil.
\end{abstract}

Keywords: Sildenafil, sperm motility, gradient centrifugation, PDE5

\section{INTRODUCTION}

Male infertility comprises any health issue in a man that lowers the chances of his female partner getting pregnant. About $15 \%$ of couples can't get pregnant with unprotected sex (Boivin et al., 2007). In about a third of infertility cases, the problem is the man (Agarwal et al., 2015). This is most often due to problems with his sperm production or their function. In particular, sperm motility is an important parameter assessed by clinicians when evaluating the male fertility potential. Asthenozoospermia is a decrease in the percentage of motile sperm in a sperm sample, and it is identified by means of a seminogram or semen analysis (Buffone et al., 2009). Over the years, several methods have been used to improve sperm motility in those patients with sperm motility defects. This includes the use of pentoxifylline, caffeine, follicular fluids, among others (Drobnis \& Nangia, 2017). Most of the time, the goal of this in vitro treatment is to increase the percentage of motile forms to improve intrauterine insemination rates, or the number of sperm recovered after sperm separation procedures such as swim up or gradients.
On the other hand, it has been twenty years since the Federal Drug Administration of the United States as the first oral agent to treat erectile dysfunction approved sildenafil citrate (Viagra ${ }^{\circledR}$, Pfizer). Sildenafil acts by blocking phosphodiesterase 5 (PDE5), an enzyme that promotes breakdown of cGMP, which regulates blood flow to the penis (Ramani \& Park, 2010) Both, in blood and seminal plasma, Sildenafil citrate concentration reaches a maximum at about 90 minutes after administration (Al-Ghazawi et al., 2007) However, the drug remains in micromolar concentrations several hours after its administrations (Al-Ghazawi et al., 2007; Gupta et al., 2005). This pharmacokinetic feature led us to investigate the possible effects of this drug on sperm function. In this regard, reports on the effects of sildenafil on sperm function are still under debate. Some investigators claim that sildenafil produce no changes (Burger et al., 2000; Glenn et al., 2009; Purvis et al., 2002) while others postulate that this dug promote an improvement in sperm motility (Cuadra et al., 2000; Dimitriadis et al., 2008).

Although the specific target for sildenafil (PDE5) was not found to be expressed in human sperm in significant levels to be detected, sperm has a wide range of phosphodiesterases involved in CGMP or CAMP, such as PDE1, PDE10, PDE11, PDE8, PDE6 and PDE4 (Buffone et al., 2014; Dimitriadis et al., 2008) The function of these phosphodiesterases in mammalian spermatozoa remains to be elucidated, but it was reported that Sildenafil's affinity and selectivity towards all PDEs currently known is much lower than what has been described for PDE5 (Wang et al., 2012). Thus, the effects found after sildenafil treatment may not be directly explained by its action on a specific phosphodiesterase and rather, by other mechanisms that involve mitochondrial function and reactive oxygen species (Sousa et al., 2014).

Despite that, some studies claim positive effects of Sildenafil on sperm motility, while others report no significant differences. We aimed to investigate the possible effects of an acute Sildenafil dose in asthenozoospermic patients.

\section{MATERIALS AND METHODS \\ Subjects}

The study protocol was approved by the Bioethics Committee of the "Dr. José Eleuterio González" University Hospital. These studies comply with the Declaration of Helsinki principles. We provided the patients with written information about the study prior to giving the informed consent. An experimental, descriptive, prospective and non-blinded study was performed in patients consulting for infertility, with ages between 20-45, that were diagnosed with asthenozoospermia according to the World Health Organization (WHO) criteria (WHO, 2010). At least two consecutive sperm analyses with percentage of motility below $40 \%(A+B)$ was used as an inclusion criterion. Those patients that were smokers, heavy alcohol consumers, were 
using any kind of medication or had chronic pathologies were excluded from the study.

Those patients that were diagnosed with asthenozoospermia after two consecutive semen analyses (samples 1 and 2) were asked to provide a new semen sample (sample 3) two weeks after the initial exams. One hour prior to the semen collection, the patients were treated orally with $100 \mathrm{mg}$ of sildenafil.

\section{Semen analysis and sample preparation}

Semen samples were obtained by masturbation after 3-5 days of sex abstinence, and analyzed following WHO recommendations (WHO, 2010). All samples fulfilled semen parameters (total fluid volume, sperm concentration, viability and morphology) according to the WHO normality criteria, with the exception of motility. Samples 2 and 3 were allowed to liquefy for $1 \mathrm{~h}$ at room temperature. Then, semen aliquots $(1 \mathrm{~mL})$ were loaded into a 45 and $90 \%$ discontinuous Pure Sperm (Nidacon) gradient (Buffone et al., 2012). Density gradients were performed by layering $0.5 \mathrm{~mL}$ of each pure sperm concentration into a $15 \mathrm{~mL}$ conical tube. The tube was then centrifuged at $300 \mathrm{~g}$ for $20 \mathrm{~min}$ at room temperature. The resulting $90 \%$ pellet was then aspirated and transferred to separate tubes. Sperm suspensions were then diluted with HTF (Irvine) medium containing 5\% HSA (Human serum albumin) and further centrifuged at $400 \mathrm{~g}$ for $10 \mathrm{~min}$ at room temperature. All samples were suspended at $0.5 \mathrm{~mL}$. An aliquot was used to assay sperm concentration and motility.

\section{Sperm motility evaluation}

Sperm motility was assessed by Computer-assisted sperm analysis (CASA), as previously described (Buffone et al., 2006). Aliquots of $5 \mu \mathrm{L}$ of the sperm suspension were placed into a Makler chamber, pre-warmed to $37^{\circ} \mathrm{C}$. CASA analysis was performed using a Hamilton-Thorne digital image analyzer (HTR-IVOS V.12B series 9617; Hamilton-Thorne Research, Beverly, MA). The settings used for the analysis were as follows: frames acquired: 30; frame rate: $60 \mathrm{~Hz}$; minimum contrast: 85; minimum cell size: 4 pixels; straightness threshold: $80 \%$; low path velocity (VAP) cutoff: $5 \mu \mathrm{m} / \mathrm{second}-1$; medium VAP cutoff: $25 \mu \mathrm{m} /$ second-1; head size, non-motile: 12 pixels; head intensity, non-motile: 130 pixels; static head size: 0.682.57 pixels; static head intensity: $0.31-1.25$ pixels; and static elongation: 23-100 pixels. The playback function of the HTR was used to accurately identify motile and immotile sperm cells. We have identified as motility type $A$, sperm that travels $25 \mu \mathrm{m} / \mathrm{sec}$ with linear direction and type $B$, sperm that travel 5-24 $\mu \mathrm{m} / \mathrm{sec}$ without defined direction.

\section{Statistical analysis}

We expressed the data as mean \pm standard deviation of the mean (SD). Statistical comparisons were performed by the Student t-test. The calculations were performed with the Libre Office 4.3.2.2 spreadsheet and the statistical analysis with the GraphPad Prism version 4.00 for Windows, GraphPad Software (San Diego, CA, USA). A probability ( $p$ ) value $p<0.05$ was considered statistically significant.

To determine an appropriate sample size, we ran a power analysis using the STATS software. As a result, a sample size of 32 individuals was necessary to conduct this study ( $95 \%$ confidence).

\section{RESULTS}

A total of 32 male patients with a diagnosis of asthenozoospermia were included in this study. General characteristics of the population such as age, time of infertility and the percentage of individuals who experienced adverse side effects because of sildenafil administration are reported in Table 1 . The reported side effects were mild headaches and flushing. However, none of these patients was excluded from this study, since these problems did not affect semen sample quality.

Table 2 depicts the basic semen parameters. There were no significant differences when the samples obtained before or after sildenafil administration were compared.

After the initial evaluation, the motile fractions were separated by density gradient centrifugation. As expected, the percentage of motile cells increases after pure sperm separation. However, the percentage of motile cells ( $A$ and $A+B)$ was significantly higher in those samples coming from individuals treated with sildenafil, when compared with the same sample obtained two weeks before this treatment (Table 3). The increase in the percentage of mobile cells seen in the sildenafil group was caused by the increase in the number of rapid cells (grade $A$ ). There were no significant difference in the percentage of slow cells $(B)$.

When the total number of motile sperm recovered $(\mathrm{M} / \mathrm{mL})$ in both conditions was compared, a significantly higher number of sperm was obtained in those samples originated from patients treated with Sildenafil (Table 3).

\section{DISCUSSION}

There are several studies assessing the influence of oral PDE5 inhibitors, such as Sildenafil, on semen parameters. However, the results are controversial and inconsistent (Tan et al., 2017). Most seminal PDE5 inhibitor's effects reported in previous studies were concentrated on sperm motility due to the well-known influence of pentoxifylline and caffeine in this parameter. Because PDE5 hydrolyzes CGMP, inhibition of PDE5 by sildenafil citrate can potentially enhance the effects of CGMP on sperm motility (Dimitriadis et al., 2008).

Previous reports demonstrated a significant effect of sildenafil on sperm motility in normospermic and asthenozoospermic patients after incubation of spermatozoa with various doses of sildenafil (Mostafa, 2007; Yang et al., 2014) Others reported no in vitro effect when using normal donors (Sousa et al., 2014). However, there is no conclusive evidence that this effect is due to PDE5 inhibition, and there are no other signaling pathways present in spermatozoa. Because the effect on sperm motility took place 2 hours after the administration of the drug, the sperm epididymal maturation and passage into the vas deferens may be excluded. Thus, this effect appears to be generated in the sperm that are present in the vas ampulla or in the seminal components released by the prostate or the seminal vesicles. Regarding the effects

Table 1. General features of individuals enrolled in this study

\begin{tabular}{|l|c|}
\hline Table 1. General features of individuals enrolled in this study & Value \\
\hline Parameter & 32 \\
\hline Patients $(\mathrm{n})$ & $32.8(24-47)$ \\
\hline Age $\left(\right.$ years) ${ }^{\dagger}$ & $56.8(18-144)$ \\
\hline Months of infertility ${ }^{+}$ & 12.5 \\
\hline Adverse side effects (\%) & \\
\hline
\end{tabular}

${ }^{\dagger}$ (medium and range). 
Table 2. Basic semen parameters before and after sildenafil administration

\begin{tabular}{|l|c|c|c|c|}
\hline Parameter & Normal & $\begin{array}{c}\text { Before sildenafil } \\
\dot{x} \pm \text { SD (range) }\end{array}$ & $\begin{array}{c}\text { After sildenafil } \\
\dot{x} \pm \text { SD (range) }\end{array}$ & p \\
\hline Volume $(\mathrm{mL})$ & $>1.5$ & $\begin{array}{c}2.45 \pm 1.4 \\
(0.3-4.8)\end{array}$ & $\begin{array}{c}2.3 \pm 1.1 \\
(0.5-4.3)\end{array}$ & $\mathrm{NS}$ \\
\hline $\begin{array}{l}\text { Concentration } \\
\left(\mathrm{x} 10^{6} / \mathrm{mL}\right)\end{array}$ & $\geq 20$ & $\begin{array}{c}67.3 \pm 102.7 \\
(0.5-505)\end{array}$ & $\begin{array}{c}48.7 \pm 38.1 \\
(0.4-150)\end{array}$ & $\mathrm{NS}$ \\
\hline Motility A (\%) & $\geq 25$ & $\begin{array}{c}11.2 \pm 8 \\
(0-24)\end{array}$ & $\begin{array}{c}14.9 \pm 15.6 \\
(0-64)\end{array}$ & $\mathrm{NS}$ \\
\hline Motility A+B (\%) & $\geq 50$ & $\begin{array}{c}21.4 \pm 13 \\
(0-40)\end{array}$ & $\begin{array}{c}24.6 \pm 18.3 \\
(0-70)\end{array}$ & $\mathrm{NS}$ \\
\hline
\end{tabular}

$\dot{\mathrm{x}} \pm$ SD average and standard deviation

Samples were compared using the Student's T-test.

NS Not significantly different

Table 3. Percentage of sperm motility after density gradient centrifugation with or without sildenafil administration

\begin{tabular}{|l|c|c|c|}
\hline Parameter & $\begin{array}{c}\text { Before sildenafil } \\
\dot{\mathbf{x}} \pm \text { SD (range) }\end{array}$ & $\begin{array}{c}\text { After sildenafil } \\
\dot{\mathbf{x}} \pm \text { SD (range) }\end{array}$ & $\boldsymbol{p}$ \\
\hline Motility A (\%) & $16.8 \pm 21.4$ & $24.8 \pm 23.9$ & $<0.050^{*}$ \\
\hline Motility B (\%) & $7.0 \pm 8.4$ & $9.0 \pm 8.4$ & $\mathrm{NS}$ \\
\hline Motility A+B (\%) & $23.8 \pm 22.9$ & $33.8 \pm 25.9$ & $<0.050^{*}$ \\
\hline Recovery (M/mL) & $5.5 \pm 6.7$ & $9.9 \pm 9.2$ & $<0.050^{*}$ \\
\hline
\end{tabular}

Samples were compared using the Student's T-test.

NS Not significantly different

$* p<0.050$ with statistical significance

of Sildenafil in vivo, several reports have demonstrated contradictory effects (Best reviewed in (Tan et al., 2017). Our results show no significant difference in baseline semen parameters before or after Sildenafil. This is in accordance with other reports that did not see major changes in semen volume, sperm concentration, sperm morphology or motility (Aversa et al., 2000). However, some authors claimed a mild improvement in some parameters, but only when Sildenafil was used chronically (Dimitriadis et al., 2008).

Others have reported a subtle increase in sperm motility after an acute administration (Pomara et al., 2007), but in concentrations around $50 \mathrm{mg}$ in contrast to the $100 \mathrm{mg}$ dose that we used in this study. Two groups reported the in vivo effect of sildenafil administration on sperm function (Aversa et al., 2000; Pomara et al., 2007). In addition, it is also reported that the beneficial effects on semen parameters only occurred in infertile individuals, and not in fertile donors (Pomara et al., 2007; Rago et al., 2012).

In this paper, we report that an acute $100 \mathrm{mg}$ sildenafil administration in asthenozoospermic patients increases the percentage of motile sperm recovered after density gradient centrifugation. This approach may be of great value in those patients with low motility and/or low sperm count, where at the end of the gradient centrifugation, a significant number of sperm is not recovered. Therefore, these patients have no other choice than end up undergoing ICSI or IVF, rather that intrauterine insemination. An acute administration of Sildenafil may produce more available motile sperm to perform intra uterine insemination or to improve the chances of success with this procedure. However, the possible positive effects on the success rate remains to be explored in future studies.

The main limitations of our study are the small number of patients, and the lack of a control group. In our study it was not possible to have a control group; however, it was required that all patients collected two semen samples within three weeks apart, to confirm asthenozoospermia; and two weeks later the patients were treated orally with sildenafil, one hour prior to the collection of a third semen sample. We could considered each patient was his own control.

\section{CONCLUSIONS}

In summary, a single oral Sildenafil treatment increases motile sperm recovery after density gradient centrifugation in asthenozoospermic patients, and may be used as an alternative strategy in assisted reproductive programs. Although chronic administration might yield better effects, this possibility remains to be determined. Large prospective randomized controlled trials are required to confirm these results.

\section{ACKNOWLEDGEMENTS}

We would like to thank the Reproduction Biology Laboratory staff, at the Monterrey University Hospital (UANL). We would also like to thank Hilda Luna Aranda, and Martha A. Cruz Rodriguez.

\section{CONFLICT OF INTEREST}

The authors declare no conflict of interest.

\section{Corresponding author}

Martha Merino Ruiz

Centro Universitario de Medicina Reproductiva Hospital Universitario "Dr. José Eleuterio González"

Universidad Autónoma de Nuevo León

Monterrey, Nuevo León, México

E-mail: mmerino_ruiz@yahoo.com.mx 


\section{REFERENCES}

Agarwal A, Mulgund A, Hamada A, Chyatte MR. A unique view on male infertility around the globe. Reprod Biol Endocrinol. 2015;13:37. PMID: 25928197 DOI: 10.1186/ s12958-015-0032-1

Al-Ghazawi M, Tutunji M, Aburuz S. Simultaneous determination of sildenafil and $\mathrm{N}$-desmethyl sildenafil in human plasma by high-performance liquid chromatography method using electrochemical detection with application to a pharmacokinetic study. J Pharm Biomed Anal. 2007;43(2):613-8. PMID: 16920325 DOI: $10.1016 / \mathrm{j}$. jpba.2006.07.028

Aversa A, Mazzilli F, Rossi T, Delfino M, Isidori AM, Fabbri A. Effects of sildenafil (Viagra) administration on seminal parameters and post-ejaculatory refractory time in normal males. Hum Reprod. 2000;15(1):131-4. PMID: 10611201 DOI: $10.1093 /$ humrep/15.1.131

Boivin J, Bunting L, Collins JA, Nygren KG. International estimates of infertility prevalence and treatment-seeking: potential need and demand for infertility medical care. Hum Reprod. 2007;22(6):1506-12. PMID: 17376819 DOI: $10.1093 /$ humrep/dem046

Buffone MG, Brugo-Olmedo S, Calamera JC, Verstraeten SV, Urrutia F, Grippo L, Corbetta JP, Doncel GF. Decreased protein tyrosine phosphorylation and membrane fluidity in spermatozoa from infertile men with varicocele. Mol Reprod Dev. 2006;73(12):1591-9. PMID: 16897700 DOI: $10.1002 / \mathrm{mrd} .20611$

Buffone MG, Doncel GF, Calamera JC, Verstraeten SV. Capacitation-associated changes in membrane fluidity in asthenozoospermic human spermatozoa. Int J Androl. 2009;32(4):360-75. PMID: 18399983 DOI: 10.1111/j.1365-2605.2008.00874.x

Buffone MG, Calamera JC, Brugo-Olmedo S, Vincentiis S, Calamera MM, Storey BT, Doncel GF, Alvarez JG. Superoxide dismutase content in sperm correlates with motility recovery after thawing of cryopreserved human spermatozoa. Fertil Steril. 2012;97(2):293-8. PMID: 22154371 DOI: $10.1016 /$ j.fertnstert.2011.11.012

Buffone MG, Wertheimer EV, Visconti PE, Krapf D. Central role of soluble adenylyl cyclase and CAMP in sperm physiology. Biochim Biophys Acta. 2014;1842(12 Pt B):2610-20. PMID: 25066614 DOI: 10.1016/j.bbadis.2014.07.013

Burger M, Sikka SC, Bivalacqua TJ, Lamb DJ, Hellstrom $W J$. The effect of sildenafil on human sperm motion and function from normal and infertile men. Int J Impot Res. 2000;12(4):229-34. PMID: 11079364 DOI: 10.1038/ sj.ijir.3900551

Cuadra DL, Chan PJ, Patton WC, Stewart SC, King A. Type 5 phosphodiesterase regulation of human sperm motility. Am J Obstet Gynecol. 2000;182(5):1013-5. PMID: 10819812 DOI: $10.1067 / \mathrm{mob} .2000 .105435$

Dimitriadis F, Giannakis D, Pardalidis N, Zikopoulos K, Paraskevaidis E, Giotitsas N, Kalaboki V, Tsounapi P, Baltogiannis D, Georgiou I, Saito M, Watanabe T, Miyagawa I, Sofikitis N. Effects of phosphodiesterase-5 inhibitors on sperm parameters and fertilizing capacity. Asian J Androl. 2008;10(1):115-33. PMID: 18087651 DOI: 10.1111/j.1745-7262.2008.00373.x
Drobnis EZ, Nangia AK. Phosphodiesterase inhibitors (PDE Inhibitors) and male reproduction. Adv Exp Med Biol. 2017;1034:29-38. PMID: 29256125 DOI: 10.1007/978-3319-69535-8_5

Glenn DR, McClure N, Cosby SL, Stevenson M, Lewis SE. Sildenafil citrate (Viagra) impairs fertilization and early embryo development in mice. Fertil Steril. 2009;91(3):8939. PMID: 18325509 DOI: $10.1016 /$ j.fertnstert.2007.12.014

Gupta M, Kovar A, Meibohm B. The clinical pharmacokinetics of phosphodiesterase-5 inhibitors for erectile dysfunction. J Clin Pharmacol. 2005;45(9):987-1003. PMID: 16100293 DOI: $10.1177 / 0091270005276847$

Mostafa T. In vitro sildenafil citrate use as a sperm motility stimulant. Fertil Steril. 2007;88(4):994-6. PMID: 17316632 DOI: $10.1016 /$ j.fertnstert.2006.11.182

Pomara G, Morelli G, Canale D, Turchi P, Caglieresi C, Moschini C, Liguori G, Selli C, Macchia E, Martino E, Francesca F. Alterations in sperm motility after acute oral administration of sildenafil or tadalafil in young, infertile men. Fertil Steril. 2007;88(4):860-5. PMID: 17544419 DOI: $10.1016 /$ j.fertnstert.2006.12.019

Purvis K, Muirhead GJ, Harness JA. The effects of sildenafil on human sperm function in healthy volunteers. $\mathrm{Br} \mathrm{J}$ Clin Pharmacol. 2002;53(Suppl 1):S53-S60. PMID: 11879260 DOI: $10.1046 /$ j.0306-5251.2001.00033.x

Rago R, Salacone P, Caponecchia L, Marcucci I, Fiori C, Sebastianelli A. Effect of vardenafil on semen parameters in infertile men: a pilot study evaluating short-term treatment. J Endocrinol Invest. 2012;35(10):897-900. PMID: 22522672 DOI: $10.3275 / 8368$

Ramani GV, Park MH. Update on the clinical utility of sildenafil in the treatment of pulmonary arterial hypertension. Drug Des Devel Ther. 2010;4:61-70. PMID: 20531962 DOI: $10.2147 /$ dddt.s6208

Sousa MI, Amaral S, Tavares RS, Paiva C, Ramalho-Santos J. Concentration-dependent Sildenafil citrate (Viagra) effects on ROS production, energy status, and human sperm function. Syst Biol Reprod Med. 2014;60(5):72-9. PMID: 24350988 DOI: 10.3109/19396368.2013.867380

Tan P, Liu L, Wei S, Tang Z, Yang L, Wei Q. The effect of oral phosphodiesterase- 5 inhibitors on sperm parameters: a meta-analysis and systematic review. Urology. 2017;105:54-61. PMID: 28259808 DOI: 10.1016/j. urology.2017.02.032

Wang $\mathrm{R}$, Burnett $\mathrm{AL}$, Heller $\mathrm{WH}$, Omori $\mathrm{K}$, Kotera J, Kikkawa K, Yee S, Day WW, DiDonato K, Peterson CA. Selectivity of avanafil, a PDE5 inhibitor for the treatment of erectile dysfunction: implications for clinical safety and improved tolerability. J Sex Med. 2012;9(8):2122-9. PMID: 22759639 DOI: $10.1111 /$ j.1743-6109.2012.02822.x

World Health Organization (WHO). WHO laboratory manual for the Examination and processing of human semen. 5th ed. Geneva: World Health Organization; 2010.

Yang $Y$, Ma $Y$, Yang $H$, Jin $Y$, Hu $K$, Wang $H X$, Wang $Y X$, Huang YR, Chen B. Effect of acute tadalafil on sperm motility and acrosome reaction: in vitro and in vivo studies. Andrologia. 2014;46(4):417-22. PMID: 23581543 DOI: 10.1111/and.12097 